\title{
The use of simulator studies to assess the impact of ITS services on road users behaviour
}

\author{
Małgorzata Pędzierska ${ }^{1, *}$, and Tomasz Kamiński ${ }^{1}$ \\ ${ }^{1}$ Motor Transport Institute, 80 Jagiellońska Str. 03-301 Warsaw, Poland
}

\begin{abstract}
The subject of this publication is the use of top-of-the-range driving simulators to study the impact of ITS services on the road safety. The aim of the article is to describe the assumptions of simulation studies carried out as part of the RID 4D project and to present the method of building research scenarios. The article discusses the catalogue of ITS services of the greatest importance to the Road Traffic Safety and traffic efficiency developed under the project. Then, services from the catalogue were specified, which were tested on the driving simulator of the Motor Transport Institute. The tests included sections of a dual-lane expressway. As a result of the work, four scenarios were created containing various dangerous events and variable message boards informing drivers about the danger and/or limiting the permitted speed. During the simulation, a set of several dozen parameters related to vehicle motion was recorded, in particular the distance to the vehicle ahead, time to collision with another vehicle or object on the road, speed, intensity of braking and acceleration. The tests were performed for good and bad weather conditions on a 60person study group. The division into age groups 18-24, 25-50 and above 50 years was applied. The research showed a difference in the way drivers of static signs and speed limits on the variable message signs affect drivers. For variable messages signs, there was a greater decrease in speed than in the case of static signs.
\end{abstract}

\section{Introduction}

The aim of the article is to describe the assumptions and methods of performing simulator tests carried out as part of the RID 4D project. The subject of the publication is using thetop-of-the-range driving simulator to evaluate the impact of ITS services on the road users behaviour. As part of the project work, a number of analyses of the state of road traffic safety in Poland were carried out. The data shows that every year, as a result of traffic incidents, several thousand people die in Poland and a dozen thousand are injured [1].

The road safety analyses conducted as part of the project show that about $95 \%$ of traffic incidents are caused by improper behaviour of the road users [1,2]. The most common causes of accidents include, among the others, non-adaptation of speed to the traffic conditions, failure to give priority to cross, incorrect overtaking, incorrect behaviour towards pedestrians, or failure to maintain a safe distance between vehicles [1].

\footnotetext{
* Corresponding author: malgorzata.pedzierska@its.waw.pl
} 
As the research carried out both in Poland and abroad proves, Intelligent Transport Systems influence the level of road safety and traffic flow as well as efficient traffic management and optimization of road network use [3,4]. Selected data on this subject can be found in the article "The use of simulator studies to assess the impact of ITS services on road users behaviour". Determining the level of road safety in Poland and the impact of ITS services on its level cannot be based solely on statistical data. Therefore, it was necessary to carry out additional analyses as well as research in order to determine the manner of implementing individual ITS services and the manner of their deployment. Under the project the tests of drivers were carried out to determine the impact of ITS services on their behaviour.

\section{Assumptions of the experiment}

As part of the work, a series of tests was planned using a high-end AS 1200-6 driving simulator. For this purpose, it was necessary to develop the assumptions of the experiment and research scenarios. The tests included sections of a two-lane expressway with a lane width of $3.5 \mathrm{~m}$, and hard shoulder of $2.5 \mathrm{~m}$ width and a design speed of $100 \mathrm{~km} / \mathrm{h} \mathrm{[5]}$. The road sections prepared have also included alternative routes. The specification was made based on Annex 1 to the Resolution of the Minister of Infrastructure of July 3, 2003 and guidelines of the General Directorate for National Roads and Motorways. Boards and variable message signs, which provide information to drivers, were placed on the prepared section.

\subsection{Compiling the research scenarios}

The area for research scenarios was made in a dedicated PreScan software. It is a simulation platform consisting of a pre-processor, based on a graphical user interface, enabling designing and modification of research scenarios and an executing environment for their construction. The main user interface for creating and testing algorithms includes MATLAB and Simulink. It is an open software platform that has flexible interfaces to connect with the dynamics model and third-party HIL equipment/simulators. The graphical user interface (GUI) allows to build scenarios and model sensors, the Matlab / Simulink interface allows to add a control system. The work in the program is based on 4 steps: scenario construction, sensor modelling, control system and launch of the experiment.

A special pre-processor (GUI) allows users to build and modify traffic scenarios in a short time. Scenarios are built from database elements using the "drag and drop" method. The database consists of:

- road sections: straight sections, curves, viaducts;

- infrastructure elements: trees, buildings, road signs;

- vehicles and road users: cars, trucks, bicycles and pedestrians,

- weather conditions: rain, snow, fog;

- $\quad$ sun light sources, headlights, street lights.

By modelling road sections, the user has the option of specifying parameters for each element. For road sections:

- number of lanes,

- adding/removing lines,

- the width of the line,

- line type (continuous, broken short, broken long),

- for broken lines: spacing between lines,

- for curves: curve length (curve radius, angle of curve),

- hard shoulder width, 
- adding barriers [6].

According to the assumptions, ITS services of the highest importance for efficiency and road safety were subject to simulation tests. A detailed list of selected services is presented in the article [7]. Due to the restrictions imposed on the driving simulator, the following services were tested: vehicle speed management, conveying traffic information to the drivers, managing adverse events, managing environmental information and communicating environmental information to the drivers. For each of the selected services, different variants of conveying the information to the driver by means of signs and boards with variable content were developed. For the vehicle speed management, a variant with a static speed limit sign, a VMS board with a speed limit, a board and repetition of the limit on the sign and a board with the reason of the limitation were selected in order to compare different types of speed limit information.

Road traffic disruption announcements (lane blocked by road works) and possible detour for alternative route were used to provide traffic information. The information on possible alternative routes was displayed in three variants: text information "recommended detour" and an arrow as well as two variants of boards with travel times difference in travel time of several percent, and twice the time difference. The experiment also included the simulation of a traffic accident when the information was passed to the driver using VMS boards and/or VMS signs. 4 variants of events were listed:

- traffic incident without displaying information about the event,

- information about the incident displayed on the board, without information about the need to change the lane and without using the speed limit sign,

- information about the incident and the need to change the lane,

- information about the incident and the need to change the lane and the sign with the speed limit.

Also various weather conditions have been modelled, such as slippery surface, reduced visibility and strong wind. The driver's behaviour was monitored in a situation where the driver did not receive information from the system and, after prior information, provided by means of VMS boards.

All boards and variable message signs have been developed based on relevant requirements and regulations. Taken into account, among the others, were signs sizes, letter sizes, spacing between them and margins. As a result of the work, 4 scenarios were created containing various dangerous events and variable message boards informing the drivers about the danger and/or limiting the allowed speed.

\section{Simulator tests}

The research group consisted of 60 people. The condition for participating in the tests was to have a valid category B driving license and to drive a minimum of $2000 \mathrm{~km}$ per year. The participants were divided into three age groups: 18-24, 25-49 and over 50 years of age. There were 20 people in each age group.

Each of the participants had 4 scenarios to go through. Two trips were conducted in good conditions and two in bad weather conditions. Before commencing the drive, each examined person was familiarized with the regulations of participation in the study and about possible side effects such as dizziness or nausea. It was also necessary to sign the consent for participation in the study and a statement on getting acquainted with the rules of using the driving simulator. Additionally, it was necessary to complete the SSQ questionnaire in order to check the well-being of the examined person. This operation was also carried out after each subsequent drive in order to detect possible symptoms of the simulator sickness. The evaluation covered, among the others, such factors as:

- general discomfort, 
- tiredness,

- drowsiness,

- headache,

- eye strain,

- difficulty with concentration,

- nausea,

- confusion,

- blurred vision,

- dizziness,

- general weakness,

- the need to take a breath,

- stomach discomfort,

- vomiting.

Each of these factors had to be assessed using the following scale:

- lack,

- slight,

- moderate,

- $\quad$ severe $[8,9]$.

If any of the factors were considered to be severe, it would be necessary to terminate the test. None of the participants had symptoms of simulator sickness, therefore all participants completed the study.

Having completed the questionnaire, the person examined was invited to the cab of the AS 1200-6 driving simulator. The next step was to conduct the familiarization and commence the test. First, an adaptation scenario was run in order to accustom people to the driving simulator and possibly exclude those with simulator sickness. After each drive there was a few minutes break, followed by the completion of the next questionnaire.

Time spent on one person ranged from 60 to 90 minutes. As a result, 60 trips were obtained: 30 in good and 30 in bad weather conditions. During the simulation, a set of several dozen parameters related to vehicle motion were recorded, in particular the distance to the vehicle ahead, time to the collision with another vehicle or object on the road, speed, intensity of braking and acceleration.

\section{Results}

The main purpose of the analyses was to determine the impact of speed-limiting signs on the behaviour of the road users. Markers were placed $200 \mathrm{~m}$ before the sign, $30 \mathrm{~m}$ before the sign, at the spot where the sign is placed, and $200 \mathrm{~m}$ behind. The arrangement of the markers is shown on the Fig 1. 


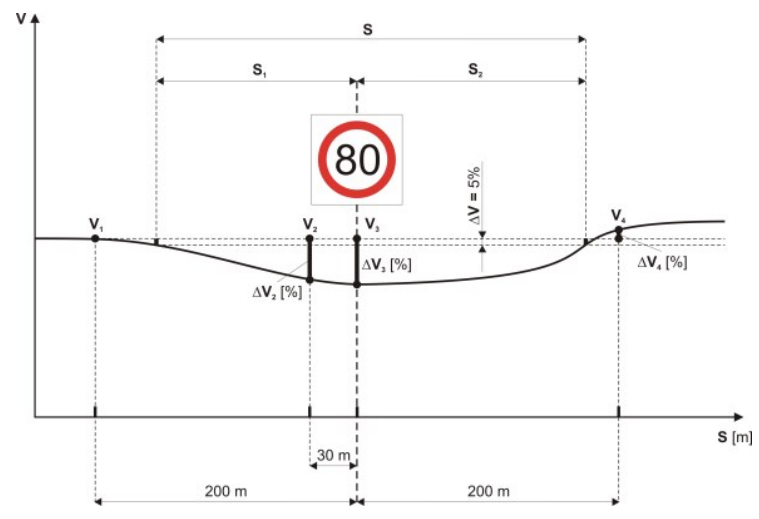

Fig. 1. Schematic layout of the markers.

In each of the points marked on the diagram, the vehicle speed and speed change were analysed. The value of the speed at a distance of $200 \mathrm{~m}$ before the sign was considered as the starting value. Speed diagrams for individual persons show significant differences in the way drivers react to speed limits. Most drivers slowed down after passing the sign/board and maintained a reduced speed for about $1200 \mathrm{~m}$. There were drivers who kept the speed at a much higher distance or did not return to a original speed at all. As expected, some drivers did not respond to speed-limiting signs regardless of their type or message. The way individual drivers reacted is presented in the diagrams.

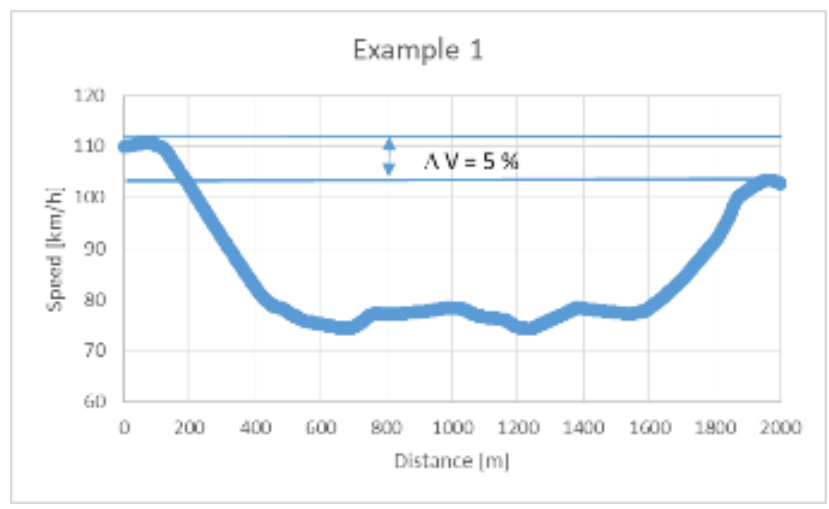

Fig. 2. Positive reaction to the speed limit.

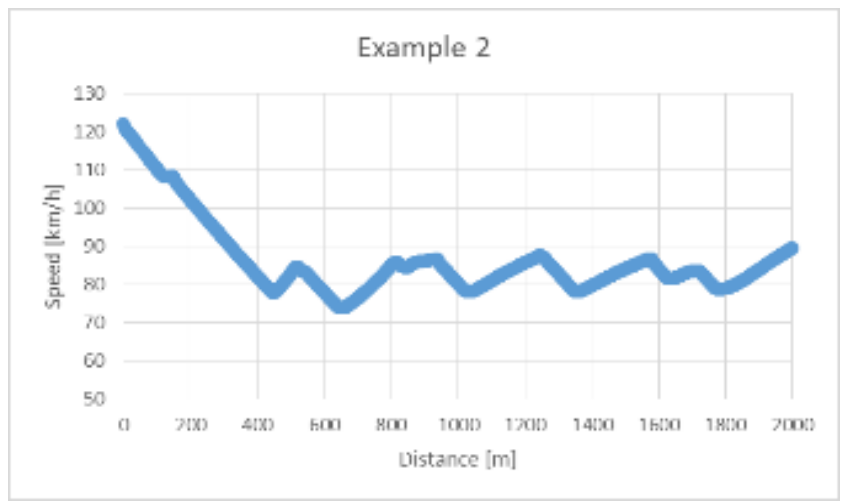

Fig. 3. Positive reaction to the speed limit. 


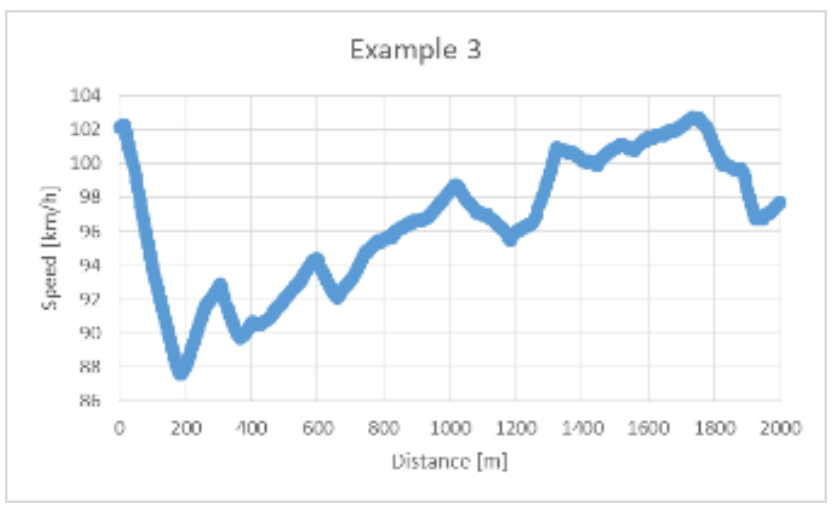

Fig. 4. Negative reaction to the speed limit

Another aspect of the study was to determine the impact of signs informing about the possibility to use an alternative route. Three ways of providing information for drivers were developed: a board with the text "Recommended detour" (Fig. 5), a board with driving times with several percent time difference (Fig. 6) and a board with driving times of twice the time length (Fig. 7).

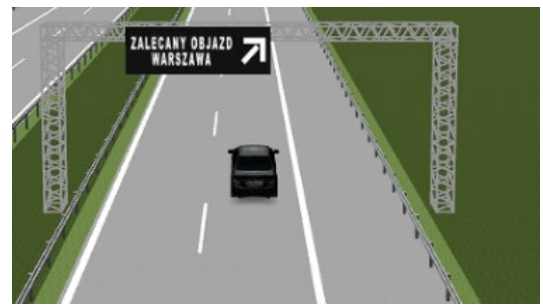

Fig. 5 A board with the text "recommended detour".

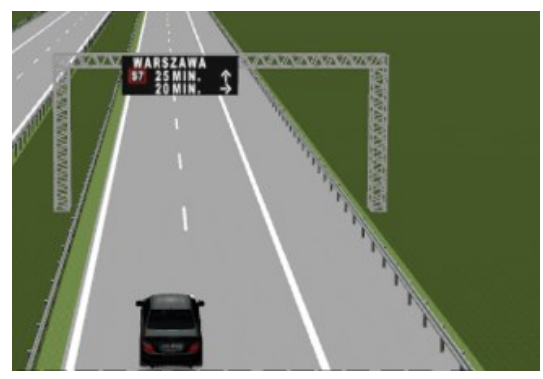

Fig. 6. A board with a small time difference.

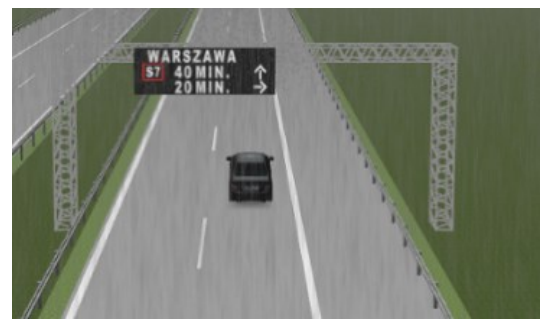

Fig. 7. A board with the twice the time difference. 
Table 1 presents the results obtained at the end of the study.

Table 1. Test results.

\begin{tabular}{|c|c|c|c|c|c|}
\hline Scenario & $\begin{array}{c}\text { Age } \\
\text { group }\end{array}$ & $\begin{array}{l}\text { Persons who } \\
\text { chose an } \\
\text { alternative } \\
\text { route }\end{array}$ & $\begin{array}{c}\text { Total } \\
\text { number } \\
\text { of people }\end{array}$ & $\begin{array}{c}\text { Percent of } \\
\text { persons going on } \\
\text { the alternative } \\
\text { route }\end{array}$ & $\begin{array}{l}\text { Results } \\
\text { for all } \\
\text { groups }\end{array}$ \\
\hline \multirow{3}{*}{$\begin{array}{c}\text { S0 - static sign } \\
\text { informing about } \\
\text { the alternative } \\
\text { route }\end{array}$} & Group 1 & 4 & 20 & $20 \%$ & \multirow[b]{3}{*}{$17 \%$} \\
\hline & Group 2 & 3 & 20 & $15 \%$ & \\
\hline & Group 3 & 3 & 20 & $15 \%$ & \\
\hline \multirow{3}{*}{$\begin{array}{l}\text { S1 - board with a } \\
\text { difference of } \\
\text { driving time of } \\
\text { several percent }\end{array}$} & Group 1 & 11 & 20 & $55 \%$ & \multirow[b]{3}{*}{$32 \%$} \\
\hline & Group 2 & 5 & 20 & $25 \%$ & \\
\hline & Group 3 & 3 & 20 & $15 \%$ & \\
\hline \multirow{3}{*}{$\begin{array}{l}\mathrm{S} 2 \text { - board with the } \\
\text { text "recommended } \\
\text { detour" }\end{array}$} & Group 1 & 17 & 20 & $85 \%$ & \multirow[b]{3}{*}{$63 \%$} \\
\hline & Group 2 & 10 & 20 & $50 \%$ & \\
\hline & Group 3 & 11 & 20 & $55 \%$ & \\
\hline $\begin{array}{l}\text { S3 - board with } \\
\text { twice the time } \\
\text { difference }\end{array}$ & Group 1 & 15 & 20 & $75 \%$ & $62 \%$ \\
\hline
\end{tabular}

Analysing the results of the research, one can notice the visible relationship between the content of the messages transmitted and the reaction of drivers. The drivers reacted most strongly to the signs informing about the much longer time of the journey through the main route and the recommended detour. There were also differences in the drivers' behaviours depending on age. Studies have shown that people in the youngest age group were more likely to choose alternative routes.

\section{Conclusion}

The use of a driving simulator for researching an impact of ITS services on the Road Safety makes it possible to conduct tests in a repeatable and safe manner. Studies have shown that drivers have reacted more strongly to the speed limits displayed on variable messages signs than speed limits on static road signs.

Studies have shown, among the others, the difference static signs and speed limits on variable content signs, affected the drivers. For variable message signs, there was a greater decrease in speed than in the case of static signs. Also the age of the drivers and atmospheric conditions had a significant influence on their behaviour. Persons in the youngest age group showed the highest inclination to bravura even in adverse weather conditions and slippery surfaces. Most of the respondents slowed down after seeing the speed limit sign, but only some of them were travelling at the allowed speed. The participants can be divided, taking their behaviour under consideration, in to persons who reduced the speed after seeing the sign and maintained this speed and then accelerated to speeds close to the original speed, persons who had slowed down and did not return to the original speed and those who ignored the speed limit.

The article presents only examples of research results. Detailed results are discussed in the article entitled: "Influence of the selected ITS services on the manner of driving a vehicle - results of the simulation tests using the-top-of-the-range driving simulators". The results were used to calibrate the Vissim/Visum/Saturn simulation software in order to carry out further analyses. The data will also be processed in detail in the SPSS software. 
The work was conducted under the Road Innovations Development program (RID) organized and funded by the National Centre for Research and Development and the General Directorate for National Roads and Motorways (contract No. DZP/RID-I-41/7/NCBR/2016).

\section{References}

1. The state of road traffic safety and activities carried out in this area in 2017, (2017)

2. Road accidents in Poland in 2017. Report of General Police Headquarters of Poland (Warsaw, 2018)

3. K.A. Harder, The Effectiveness and Safety of Traffic and Non-traffic Related Messages Presented on Changeable Message Signs (CMS). Publication MN/RC-200427 (Minnesota Department of Transportation, 2003)

4. G.F. Ulfarsson, S. V. N., V. P., The Effect of Variable Message Signs on the Relationship Between Mean Speeds and Speed Deviations, in: 81st Annu. Meet. Transp. Res. Board, p. 29 (2002)

5. Annex No. 1 of the Decree of the Minister of Infrastructure of July 3, 2003 and guidelines of the General Directorate for National Roads and Motorways (2003)

6. PreScan Manual, R7.1.3, (2015)

7. M. Pędzierska, T. Kamiński, K. Gąsiorek, E. Szmidt, P. Razin, The concept of assessing the impact of intelligent transport systems on road safety and traffic efficiency using high-end driving simulators (in Polish), Autobusy. 6 pp. 1253-1257 (2017)

8. R.S. Kennedy, N.E. Lane, K.S. Berbaum, M.G. Lilienthal, A simulator sickness questionnaire (SSQ): A new method for quantifying simulator sickness, Int. J. Aviat. Psychol. 3(3) pp. 203-220 (1993)

9. M. Kruszewski, P. Razin, M. Niezgoda, E. Smoczyńska, K. T., Simulator sickness occurrence and effects analysis during Drivers research, Syst. Logistyczne Wojsk. 44 pp. 188-201 (2016) 